\section{JOSÉ MANUEL AIZPÚRUA Y JOAQUÍN LABAYEN: STUDIO DE ARQUITECTURA. 1928. ARQUITECTURA Y MOBILIARIO EN LOS ALBORES DE LA MODERNIDAD}

\section{Francisco Javier Muñoz Fernández}

Universidad del País Vasco (UPV/EHU)

Resumen: El estudio de trabajo que en 1928 José Manuel Aizpúrua y Joaquín Labayen construyeron en San Sebastián, fue el manifiesto y el ensayo de lo que quería ser la nueva arquitectura. En él se plasmó una concepción de la arquitectura, del trabajo del arquitecto, del espacio y del mobiliario desconocidos hasta entonces en el panorama arquitectónico local. El estudio fue también el laboratorio de proyectos posteriores y un reclamo publicitario y propagandístico, que con el auxilio de otras iniciativas quiso seducir a posibles clientes y facilitar el desarrollo de las ideas de los arquitectos guipuzcoanos.

Palabras clave: José Manuel Aizpúrua, Joaquín Labayen, arquitectura, mobiliario, racionalismo, Donostia- San Sebastián.

Abstract: The architecture studio that Jose Manuel Aizpurua and Joaquin Labayen built in 1928 in San Sebastian, was a manifesto and an essay of the modernity of the new architecture in their country. In the studio the architects show a new conception of architecture, the profession, space and furniture that until them were unknown in the local architectonic panorama. The studio was the laboratory of experimentation for forthcoming projects as well as a with other initiatives wanted to seduce potential clients and provide the development of Aizpurua and Labayen's architectural ideas.

Keywords: Jose Manuel Aizpurua, Joaquin Labayen, indoor architecture, furniture, modern movement, San Sebastian.

Laburpena: 1928an Jose Manuel Aizpurua eta Joaquin Labayenek Donostian eraiki zuten bere lan egiteko estudioa arkitektura berriak izan nahi zuen entsegua eta manifestua izan zen. Bertan ordura arte inguruan ezezagunak ziren arkitektura, arkitektoaren lana, espazioa eta altzariak ulertzeko modu berria gertu zen. Estudioa beranduago egin ziren proiektuen laborategia izan zen ere eta, beste ekimenekin batera, bezeroak seduzitu eta arkitekto gipuzkoarren ideiak garatzea ahalbideratu nahi zuen publizitate eta propaganda erakarpena ere.

Gako-hitzak: Jose Manuel Aizpurua, Joaquin Labayen, arkitektura, altzarigintza, arrazionalismoa, Donostia. propagandistic and advertising slogan, which together
Jose Manuel Aizpurua \& Joaquin Labayen: Architecture Studio. 1928. Architecture and Furniture in the Beginning of Modernism

Jose Manuel Aizpurua eta Joaquin Labayen: Arkitektura studioa. 1928. Arkitektura eta altzarigintza modernotasunaren hastapenetan 
En 1928 Azorín publicó Félix Vargas: etopeya, una novela moderna y experimental que se desarrolla en San Sebastián ${ }^{1}$. El espacio escogido por Azorín como escenario de modernidad no fue casual. En aquellos años, entre finales de los años veinte e inicios de la década de los años treinta, la capital guipuzcoana fue una ciudad, en palabras de la escritora Irène Némirovsky, cosmopolita ${ }^{2}$, que se convirtió en el principal foco artístico en el País Vasco y en un animado lugar de encuentro de muchos creadores, especialmente, durante el período estival. En este ambiente, junto con la primera poesía de Gabriel Celaya, la moda de Cristóbal Balenciaga, la escultura de Jorge Oteiza, la pintura de Jesús Olasagasti, la pintura y fotografía de Nicolás de Lecuona, también destacó la arquitectura de José Manuel Aizpúrua y su colaborador Joaquín Labayen.

Precisamente en 1928 los arquitectos guipuzcoanos construyeron su propio estudio de arquitectura, una atrevida propuesta neoplasticista, que al igual que la novela de Azorín también fue un ensayo de modernidad. La actividad de Aizpúrua y Labayen, que iniciaron un año antes, en 1927, no se limitó a proyectos que generalmente no construyeron, y se completó con viajes, publicaciones, conferencias, exposiciones y colaboraciones que tuvieron como objetivo propiciar el ambiente necesario para que se desarrollara una arquitectura, similar a la que habían concretado con su centro de trabajo, y de la que querían ser sus principales artífices.

José Manuel Aizpúrua (San Sebastián, 1902- 1936) y Joaquín Labayen (Tolosa, 1900-1996) terminaron sus estudios de arquitectura en Madrid en el verano de $1927^{3}$. Los amigos y compañeros no tardaron abrir en San Sebastián, bajo el liderazgo de Aizpúrua, su estudio conjunto de arquitectura. La obra, ideada en marzo de 1928 fue la primera obra construida de los arquitectos y toda una declaración de intenciones. Al poco tiempo su espacio de trabajo se convertiría en un lugar de encuentro y referencia para muchos artistas ${ }^{4}$; ya que la inquietud y los intereses de Aizpúrua por otras artes, la poesía ${ }^{5}$, la música, el deporte ${ }^{6}$, o los viajes ${ }^{7}$, le llevaron a conocer y relacionarse con muchos creadores.

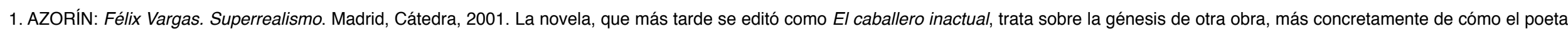

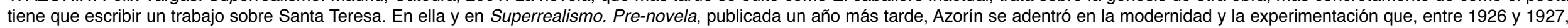
publicaron otros autores como Ramón Gómez de la Serna, Pedro Salinas, Benjamín Jarnés o Antonio Espina.

2. Así lo describe Némirovksy en su novela de 1926 Malentendido. NÉMIROVSKY, I.: Malentendido. Barcelona, Salamandra, 2013 , p. 24.

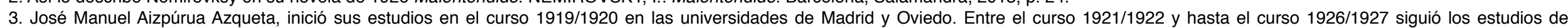

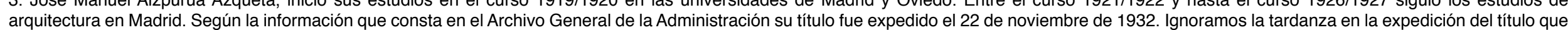

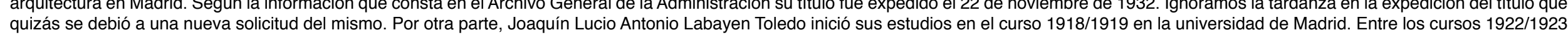

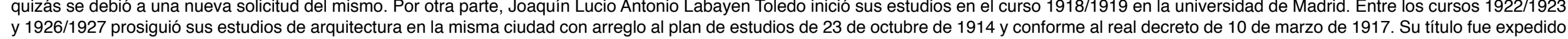
el 12 de septiembre de 1927. Archivo General de la Administración (AGA). (05) 020, 32/14956, 8109-15, y (05) 020, 32/14778, 7715-34.

4. El estudio fue lugar de encuentro y reunión de los artistas Jesús Olasagasti, Juan Cábanas Erausquin y, en menor medida, Jorge Oteiza. Asimismo, es posible que la gestación en 1933 del fallido Grupo

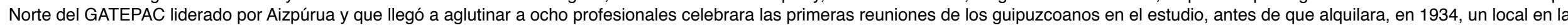
misma calle Prim de la capital guipuzcoana. "El grupo vasco del gatepac ha quedado formado de la siguiente forma. Aizpúrua, Labayen, Lagarde, Vallet, Ponte, Olazábal, Baroja, Alberdi de San Sebastián. Vallejo, Madariaga Bilbao de Bilbao. Zarranz de Pamplona. Tenemos grandes proyectos y muchas ilusiones, vamos a empezar por preparar para toda Euskadi escuelas rurales, grupos escolares, escuelas de trabajo fechada el 28.12.1933. Las referencias al local del grupo aparecen en la carta de Jose Manuel Aizpurua a Josep Lluis Sert fechada el 05.03.1934. Arxiu Historic COAC (AHC). GATCPAC. Correspondencia. OTEIZA, J.: "Recuerdo y olvido de José Manuel Aizpúrua", Nueva Forma, 40, mayo de 1969, monográfico dedicado a José Manuel Aizpúrua sin paginar. OTEIZA, J.: "Entrevista con Oteiza", Garaia, 23, del 4 al 9 de febrero de 1977, pp. 26-35. Sobre el arte de la época se puede consultar: MOYA, A.: Orígenes de la vanguardia artística en el País Vasco. Nicolás de Lekuona y su tiempo. Madrid, Electa, 1994. 
Uno de los primeros viajes de Aizpúrua al extranjero fue en 1927, poco después de terminar sus estudios y antes de proyectar el estudio. Lo hizo a Holanda y Bélgica, visitando las ciudades de Ámsterdam, Haarlem, La Haya, Rotterdam, Utrecht y Bruselas. En su viaje llevó una cámara Kodak que ese mismo año le regaló su tío Floro Azqueta y que propició el interés de Aizpúrua por la fotografía ${ }^{8}$. Con ella el joven arquitecto fotografió en Holanda edificios de Marnette, De Klerk, Wijdeweld, Wills, el ensayo neoplasticista de la casa Schörder de Gerrit Rietveld en Utrecht, y diferentes locales comerciales ${ }^{9}$.

La moderna arquitectura holandesa que Aizpúrua visitó y retrató, seguramente la conoció, previamente, a través de diferentes revistas profesionales ${ }^{10}$. Así pudo suceder con Arquitectura (1918-1936) en la que, a partir de abril de 1927, se publicaron varios artículos del artista y agitador neoplasticista Theo Van Doesburg quien se encargó, a su vez, de dar a conocer la arquitectura española en el magacín holandés Het Bouwbedrijf (1924-1931) ${ }^{11}$.

Uno de los artículos que publicó la revista madrileña, y también recogieron otras publicaciones profesionales, estaba ilustrado con una llamativa axonometría, originariamente coloreada, de un hotel que Doesburg y Cornelius Van Eesteren realizaron en $1923^{12}$. Este modo de representación, también utilizado por Rietveld, fue más conocido que cualquier otra proyecto neoplasticista, y llegó a convertirse en manifiesto y en sinónimo de modernidad, que los principales arquitectos de vanguardia de los años veinte adoptaron como reclamo visual de una arquitectura que todavía estaba por llegar. Así lo hicieron Aizpúrua y Labayen en sus primeros proyectos de 1927-1928, como también lo hicieron otros profesionales vascos de la época, como el arquitecto bilbaíno Luis Vallejo, amigo y compañero de promoción de los arquitectos guipuzcoanos ${ }^{13}$.

5. En palabras de Gabriel Celaya, Aizpúrua fue un gran impulsor de la nueva poesía. CELAYA, G.: Poesía y verdad. Papeles para un proceso. Barcelona, Planeta, 1979, p. 149.

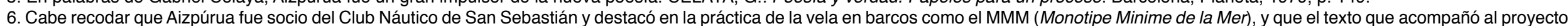

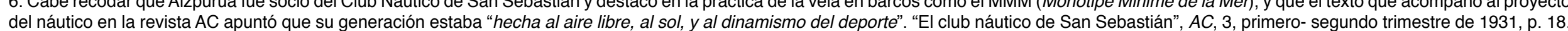

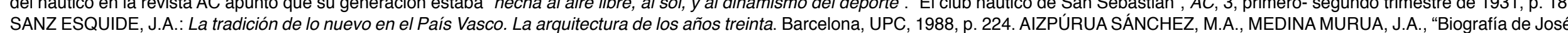
SANZ ESQUIDE, J.A.: La tradición de lo nuevo en el País Vasco. La arquitectura de los años treinta. Barcelona, UPC, 1988, p. 224. AIZPURUA SANCHEZ, M.A., MEDINA MURUA, J.A., "Bio
Manuel Aizpúrua Azqueta”, en SANZ ESQUIDE, J.A. (comisario): José Manuel Aizpúrua fotógrafo. La mirada moderna. Madrid, Museo Nacional Centro de Arte Reina Sofía, 2004, p. 44.

7. Sobre los viajes de Aizpúrua se puede consultar: MEDINA MURUA, J.A.: José Manuel Aizpúrua y Joaquín Labayen. San Sebastián, COAVN. Gipuzkoa. Diputación Foral de Gipuzkoa, 2011, pp. 129-130. 8. Al respecto se puede consultar: José Manuel Aizpúrua fotógrafo. La mirada moderna, opus cit., 2004. Catálogo de la exposición comisariada por José Ángel Sanz Esquide. Del mismo autor se pueden consultar: MEDIETA, J. M., OLAZABAL, M., SANZ ESQUIDE, J. A.: Archivo de Arquitectura en el País Vasco. Años 30. Vitoria, Gobierno Vasco, 1990. SANZ ESQUIDE, J. A., "Temporalidad e intemporalidad en la obra de José Manuel Aizpúrua", 3ZU: revista d’arquitectura, 4, 1995, pp. 46-55. SANZ ESQUIDE, J. A.: Real Club Náutico de San Sebastián, 1928- 1929, Almería, Colegio de Arquitectos de Almería, 1995. SANZ ESQUIDE J. A "El periodo heroico de la arquitectura moderna en el País Vasco (1928-1930)", Ondare, 23, 2004, pp. 77-90.

9. MEDINA MURUA, J.A.: José Manuel Aizpúrua y Joaquín Labayen, opus cit., pp. 129-131.

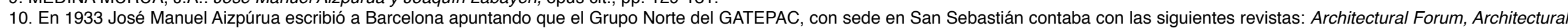

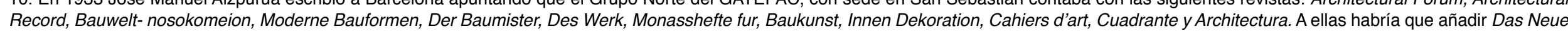
Frankfurt que aparece fotografiada repetidas veces en el estudio y otras que llegarían a diferentes bibliotecas de la capital. Carta de José Manuel Aizpúrua a Josep Torres fechada el 1 de febrero de 1934. AHC. GATCPAC. Correpondencia. Asimismo sobre las publicaciones que manejaban Aizpúrua y Labayen se puede consultar: MEDINA MURUA, J.A.: "La libreta de Labayen y Aizpúrua. Un antecedente de la influencia alemana en la arquitectura española", en POZO, J.M., LÓPEZ, I. (coord.): Modelos alemanes e italianos para España en los años de postguerra. Pamplona, t6, 2004, pp. 207-214.

11. DOESBURG, T.: On European Architecture. Complete Essays from Het Bouwbedriff 1924-1931. Basilea, Birkhauser, 1990.

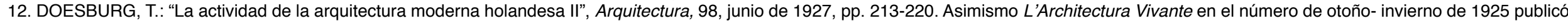
alguno de estos proyectos.

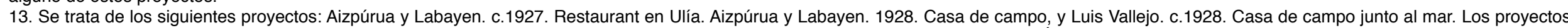

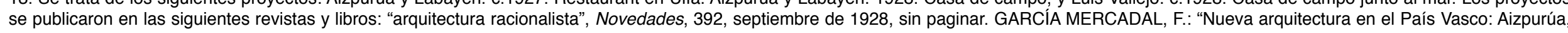
Labayen y Vallejo", Arquitectura, 115, noviembre de 1928, pp. 358-362. La maqueta del restaurante y el estudio de los arquitectos guipuzcoanos apareció en: "Restaurant piscina en el Monte Ulía. Arquitectos: Labayen y Aizpúrua”, Cortijos y Rascacielos, 10, otoño de 1932, p. 108 y “Arquitectura moderna en San Sebastián”, Cortijos y Rascacielos, 4, primavera de 1931, pp. 104-105. A la vez que 
En consecuencia, la elección de Aizpúrua para viajar a Holanda no fue casual, como tampoco lo fue que Doesburg publicara en una revista marginal como Arquitectura. Fernando García Mercadal, redactor del boletín y uno de los principales anunciadores y prosélitos del racionalismo en España, fue el responsable de que el pintor holandés colaborase con la revista, y que pronunciase una conferencia en la Residencia de Estudiantes de Madrid en mayo de 1930, donde también estuvieron Le Corbusier (1928), Erich Mendelsohn (1929) ${ }^{14}$ y Walter Gropius (1930). Asimismo, el activismo de Mercadal le llevó a pronunciar conferencias a favor de la nueva arquitectura, como las que se celebraron en mayo de 1928 en Bilbao y San Sebastián ${ }^{15}$.

En aquellas conferencias Mercadal, seguramente, coincidió con Vallejo y con Aizpúrua y Labayen, que estaban construyendo su centro de trabajo. Al poco tiempo, a partir del mes de julio, los tres arquitectos presentaron sus primeras propuestas en la Exposición de Artistas Vascos que se celebró en la capital guipuzcoana ${ }^{16}$. En el mes de septiembre la revista donostiarra Novedades, recogió los proyectos de los profesionales guipuzcoanos en un artículo, presumiblemente elaborado por Aizpúrua que llevaba por título "arquitectura racionalista" ${ }^{\prime 17}$. Una de las dos páginas del artículo estaba ilustrada con un fotomontaje que resumía las influencias del arquitecto donostiarra: la casa Schröder de Gerrit Rietveld, la Bauhaus de Walter Gropius, y la casa de Le Corbusier y Pierre Jeanneret para la exposición de Weissenhof de Stuttgart de 1927 que organizó Ludwig Mies, y que Aizpúrua visitó en otros de sus viajes $^{18}$.

Seguidamente, en noviembre de 1928, García Mercadal firmaba en Arquitectura un artículo con las propuestas que Vallejo, Aizpúrua y Labayen le proporcionarían, y señalaba a Robert Mallet- Stevens como otro de los referentes de su arquitectura ${ }^{19}$. De hecho, el artículo de Mercadal también recogió el proyecto del casino de San Juan de Luz del arquitecto francés

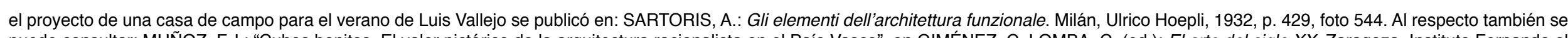

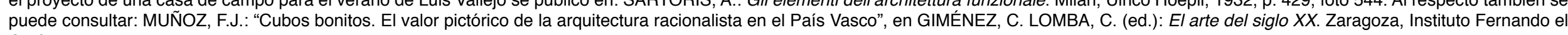
Católico. Universidad de Zaragoza, 2009, pp. 519-535.

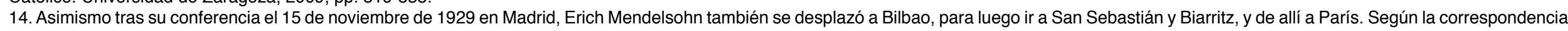

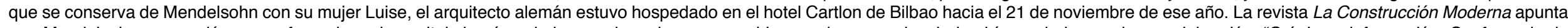

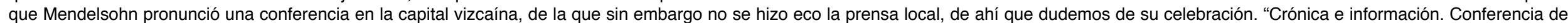

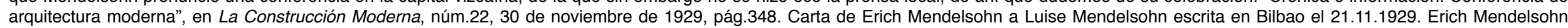
Archive (EMA). Correspondencia entre Erich y Luise Mendelsohn 1910-1953. Kunstbibliothek SMB. The Getty Research Institute.

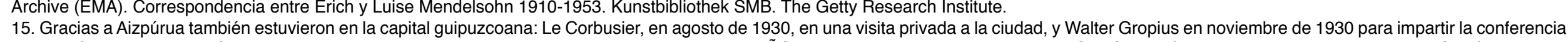

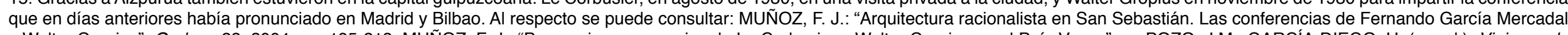

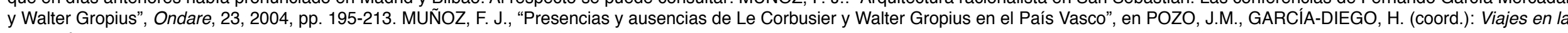
transición de de la arquitectura española hacia la modernidad. Pamplona, t6, 2010, pp. 457-464.

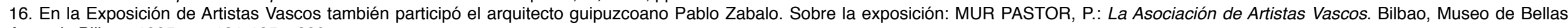
Artes de Bilbao, 1985, pp. 131-135 y 280.

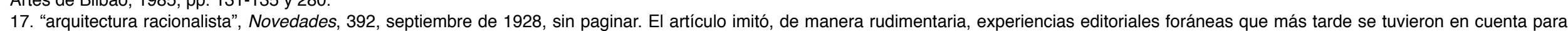
elaborar la revista AC (1931-1937) en la que colaboró Aizpúrua.

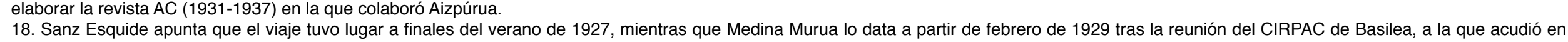

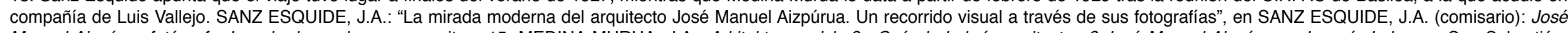

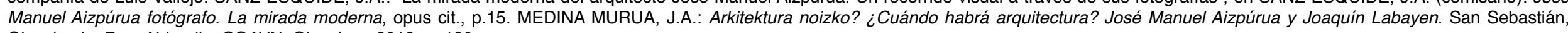
Gipuzkoako Foru Aldundia. COAVN. Gipuzkoa, 2012, p. 130.

19. GARCÍA MERCADAL, F., opus cit. El artículo está firmado en octubre del mismo año. 
inaugurado en el verano de 1928, que presentaba una decoración interior y equipamiento de mobiliario igualmente modernos ${ }^{20}$.

Sin embargo, Aizpúrua y Labayen, que Mercadal presentó como los adalides de un cambio del panorama arquitectónico en el País Vasco, tan sólo habían construido su propio estudio de trabajo (Fig.1 y 2), y el menos atrevido

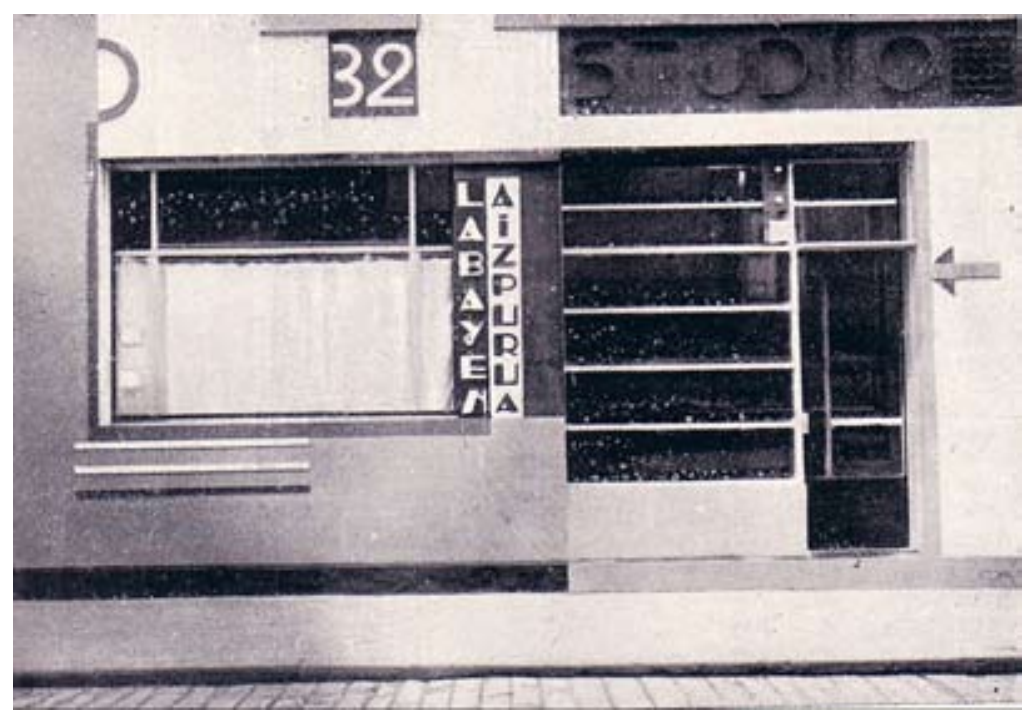

Fig. 1) Studio de Arquitectura. José Manuel Aizpúrua y Joaquín Labayen. 1928. Publicado en la revista Arquitectura en noviembre de 1928

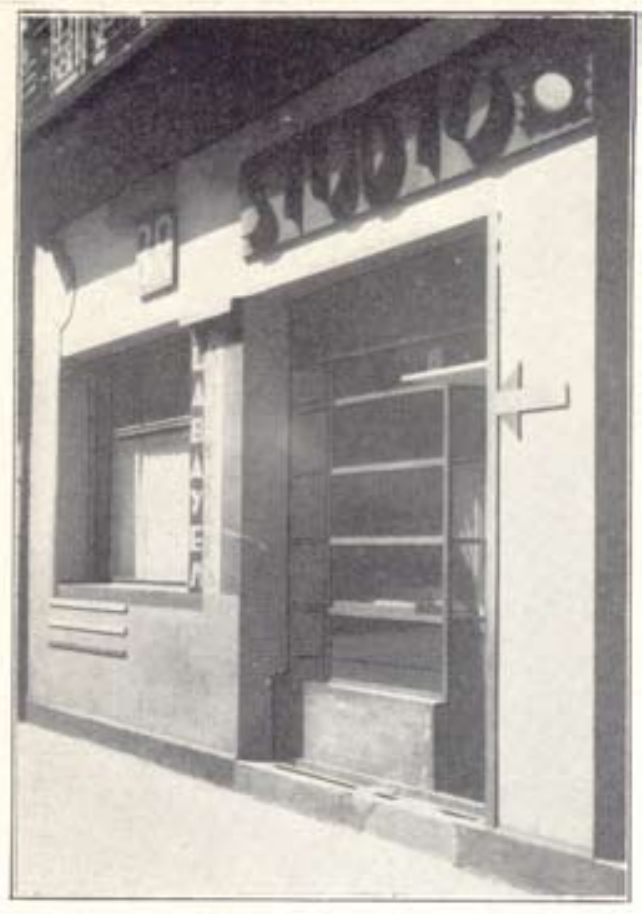

Fig. 2) Studio de Arquitectura. José Manuel Aizpúrua y Joaquín Labayen. 1928. Publicado en la revista Cortijos y rascacielos en la primavera de 1931

20. El proyecto de Mallet-Stevens se publicó en varias revistas españolas: GARCíA MERCADAL, F., opus cit., EE, "Exposición de arquitectura moderna”, La Construcción Moderna, 18, 30 de septiembre de 1930, pp.276-278. El arquitecto francés ya era conocido gracias a las revistas Arquitectura y La Gaceta Literaria, que publicaron algunas de sus obras y opiniones: BERGAMíN, Rafael: "Eso no es arquitectura", Arquitectura, 63, julio de 1926, pp. 208-211, donde se recoge un proyecto de Villa que no llegó a realizarse de Mallet- Stevens publicado en verano de 1924 en la revista francesa $L$ 'Architecture Vivante conocida y leída en España. MALLET-STEVENS, R.: "Las razones de la arquitectura", Arquitectura, 92, diciembre de 1926, pp. 470-484. MALLET-STEVENS, R.: "Dice Mallet- Stevens", La Gaceta

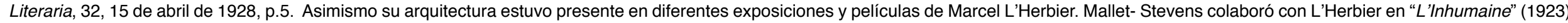
y "Le Vertige" (1926), cuyos fotogramas se publicaron en la revista Arquitectura. Cabe recordar que en 1931 se presentó Trilogie de l'architecture moderne de Pierre Chenal donde aparecían las villas Stein

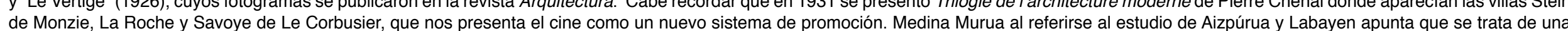

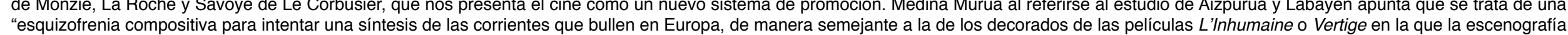
"esquizofrenia compositiva para intentar una síntesis de las corrientes que bullen en Europa, de manera semejante a la de los decora 
Dancing y Cabaret Tabarín del Frontón del Urumea en San Sebastián que también recogió la revista ${ }^{21}$.

El estudio de arquitectura que tan sólo podemos reconstruir gracias a las fotografías ${ }^{22}$ y los escasos planos conservados (Fig.3) ${ }^{23}$, fue un manifiesto de lo que quería ser la nueva arquitectura. En su propuesta los arquitectos utilizaron las llamativas formas geométricas, sencillas y coloridas del neoplasticismo que Aizpúrua acabada de visitar, y empezaron a ensayar en sus primeros proyectos. El resultado fue una propuesta que presentaba una concepción formal, pero también espacial y del mobiliario desconocida hasta entonces en la capital guipuzcoana, y también una manera diferente de entender la arquitectura. De hecho, la carta de presentación de la modernidad en la capital guipuzcoana fue un proyecto de arquitectura interior, esto es, un elemento en la época considerado menor, propio de decoradores, pero que los profesionales guipuzcoanos presentaron y defendieron, no sin cierto esnobismo, como objeto privilegiado de su trabajo ${ }^{24}$, que por otra parte era el modo más fácil y directo, sino el único, en el que inicialmente pudieron concretar sus ideas.

El interés de Aizpúrua por los locales comerciales está presente en proyectos de esta misma época como "Mayte Studio. Representaciones"25 (Fig.4), que

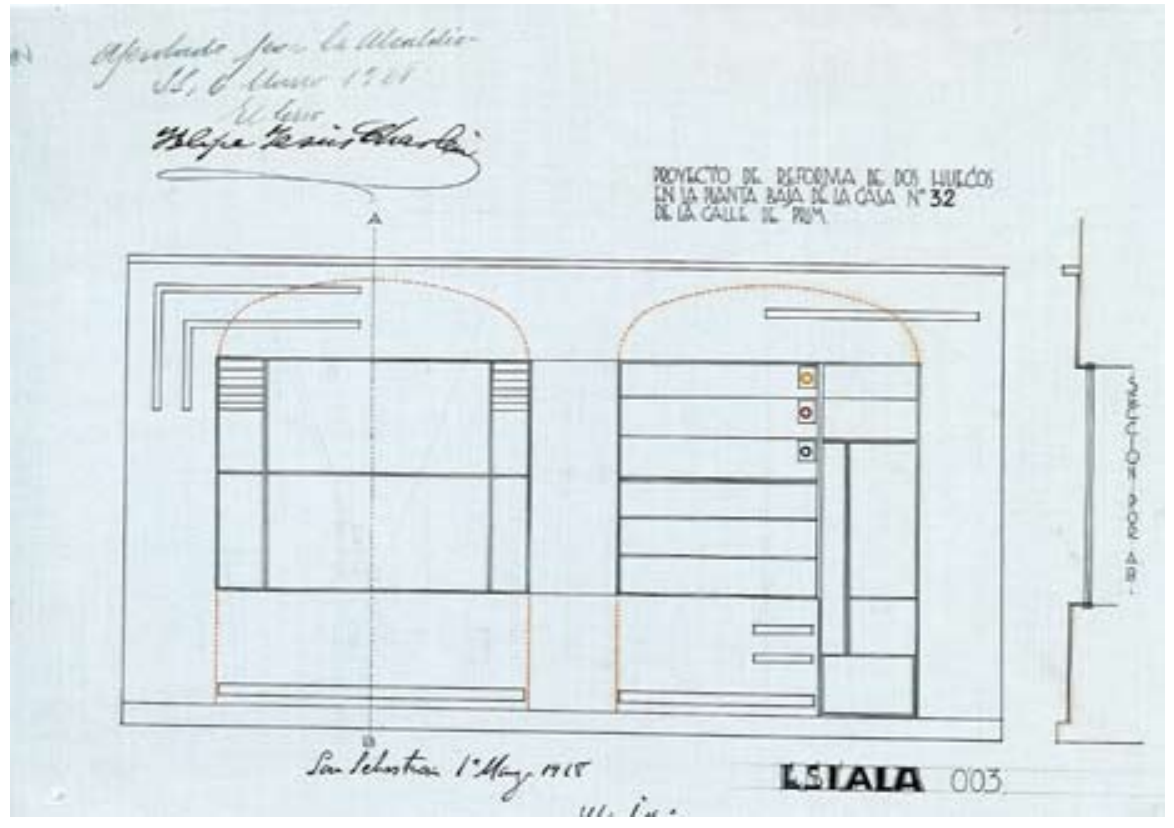

Fig. 3) Fachada del Studio de Arquitectura. José Manuel Aizpúrua y Joaquín Labayen 1928. Archivo Municipal de San Sebastián. Donostiako Udal Artxiboa. D-11, 2431-9

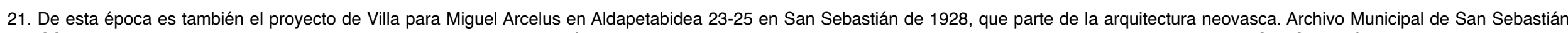

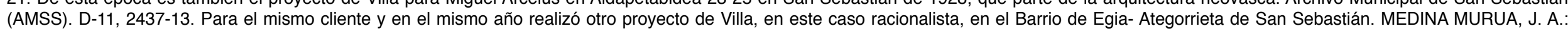
Arkitektura, noizko? ¿Cuándo habrá arquitectura? José Manuel Aizpúrua y Joaquín Labayen, opus cit., p. 78.

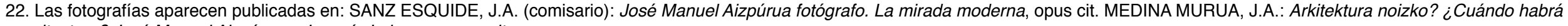
arquitectura? José Manuel Aizpúrua y Joaquín Labayen, opus cit.

23. AMSS. D-11, 2431-9.

24. "Los profesion

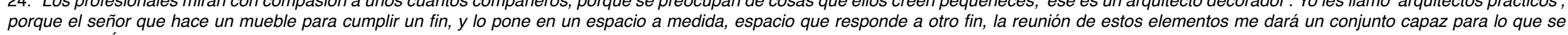
pensó”. AIZPÚRUA AZQUETA, J.M.: “¿Cuándo habrá arquitectura?", La Gaceta Literaria, 77, 1 de marzo de 1930, p. 9.

25. Biblioteca Nacional de España (BNE). DIB.018.001.6414. 


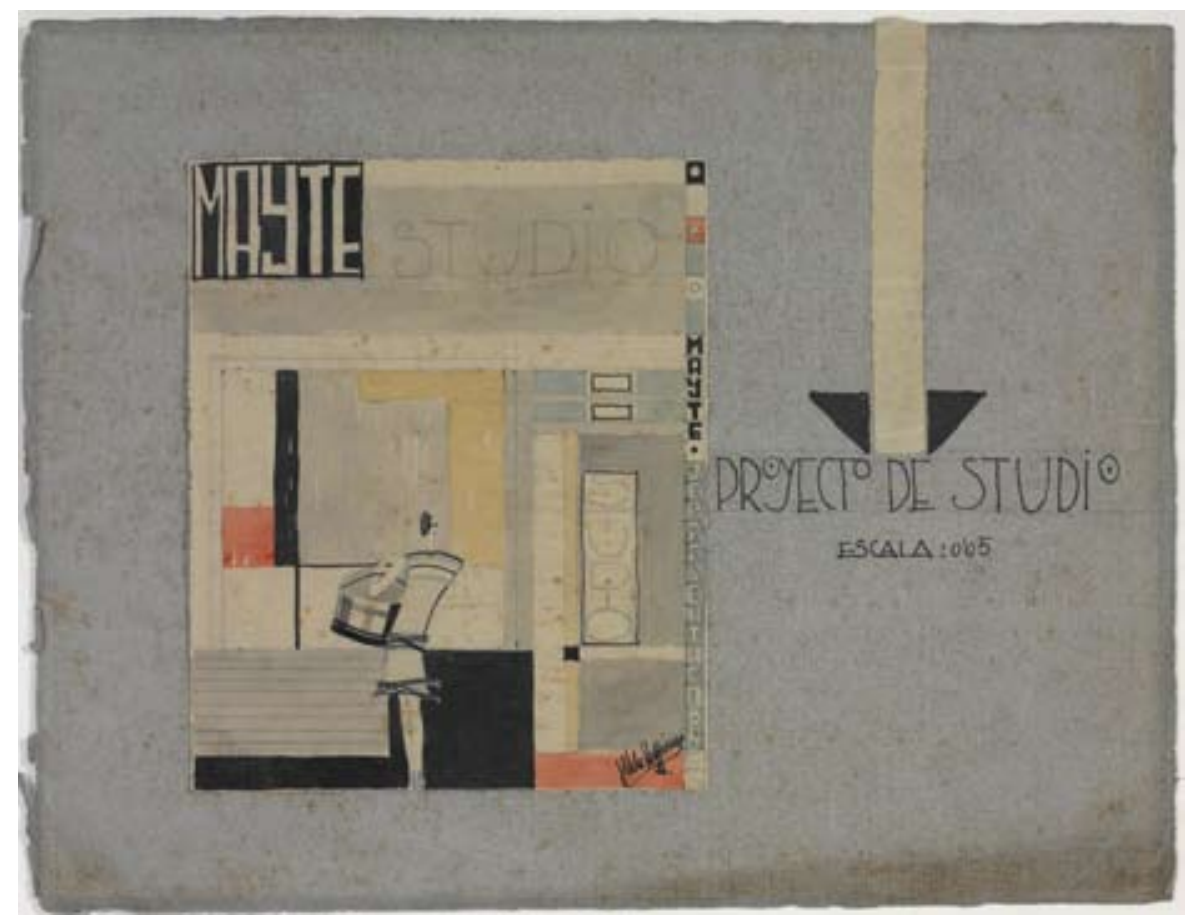

Fig. 4) Maye Studio. José Manuel Aizpurua. 1928. Biblioteca Nacional de España. DIB.018.001.6414 guarda muchas similitudes con su despacho, o los que recoge en su carné de dibujos de $1928^{26}$.

El nombre del centro de trabajo de los arquitectos, "studio", al igual que el ideado para otros comercios de la época, además de resultar llamativo quería ser identificable y comprensible en diferentes idiomas, por lo que resumía la concepción cosmopolita, nueva y abierta que Aizpúrua y Labayen tenían de su profesión. Igualmente extraña resultaría la ubicación del estudio, en los bajos comerciales de una casa de vecindad que ocupaba una de las principales arterias de la ciudad, el número 32 de calle Prim. El lugar de trabajo se alejaba así del habitual despacho aislado de otros colegas.

Se trató, en definitiva, de una sofisticada y moderna "boutique" de arquitectura donde el transeúnte, tal como podemos observar en un dibujo de Aizpúrua (Fig.5), podía ver los trabajos expuestos en su escaparate (generalmente a través de maquetas y proyectos), o el modo en que trabajaban los arquitectos ${ }^{27}$. En consecuencia, con el estudio Aizpúrua y Labayen se trasladaron a la calle, cerca del público y de los clientes, que todavía no tenían y a los que querían seducir. Fue un modo más, junto con las publicaciones y las exposiciones en las que estaban participando, con el que publicitar de manera llamativa y sugestiva una arquitectura todavía en gestación y que voluntariamente rompía con el pasado más cercano. De hecho, la fachada del estudio, de escasa superficie a la calle, poco tenía que ver con el establecimiento de

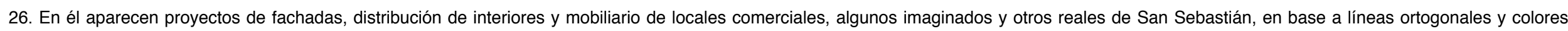

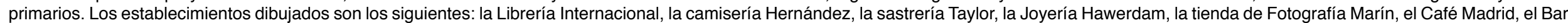

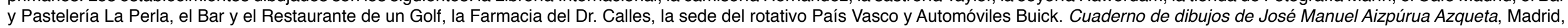
Museo Nacional Centro de Arte Reina Sofía, 2004.

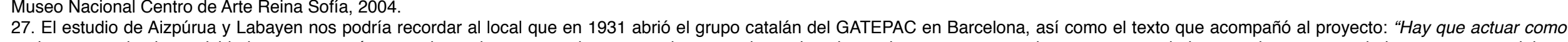

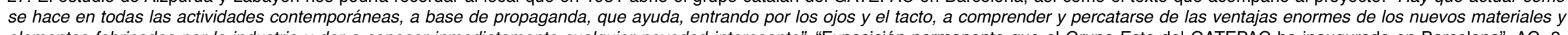

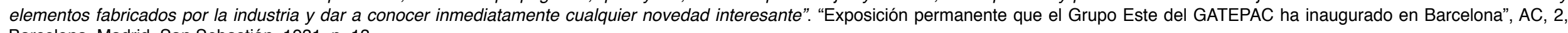
Barcelona. Madrid. San Sebastián, 1931, p. 13. 


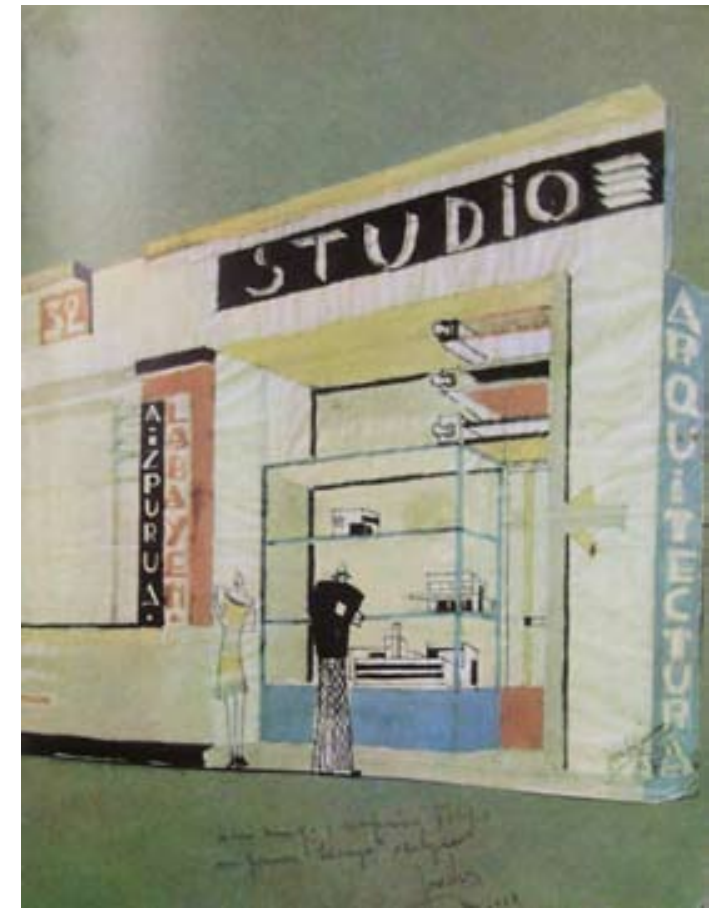

Fig. 5) Boceto del Studio de Arquitectura.

José Manuel Aizpúrua. 1928. Publicado en la revista Nueva Forma en 1969

tapicería contiguo. Una foto, seguramente tomada por el propio Aizpúrua y remitida a Doesburg, quizás a través de Mercadal, se publicó en marzo de 1930 en la revista Het Bouwbedrijf8 ${ }^{8}$ (Fig.6). En la fotografía se puede apreciar la diferencia y el cambio que supuso la propuesta de Aizpúrua y
Labayen en la época, donde los materiales, las formas, los colores y la tipografía eran totalmente diferentes, y en consecuencia un reclamo seguro para el viandante ${ }^{29}$.

La superficie abierta a la calle del estudio, sobresalía de la línea de fachada del edificio y destacaba por su el uso de carpintería metálica, que no fue

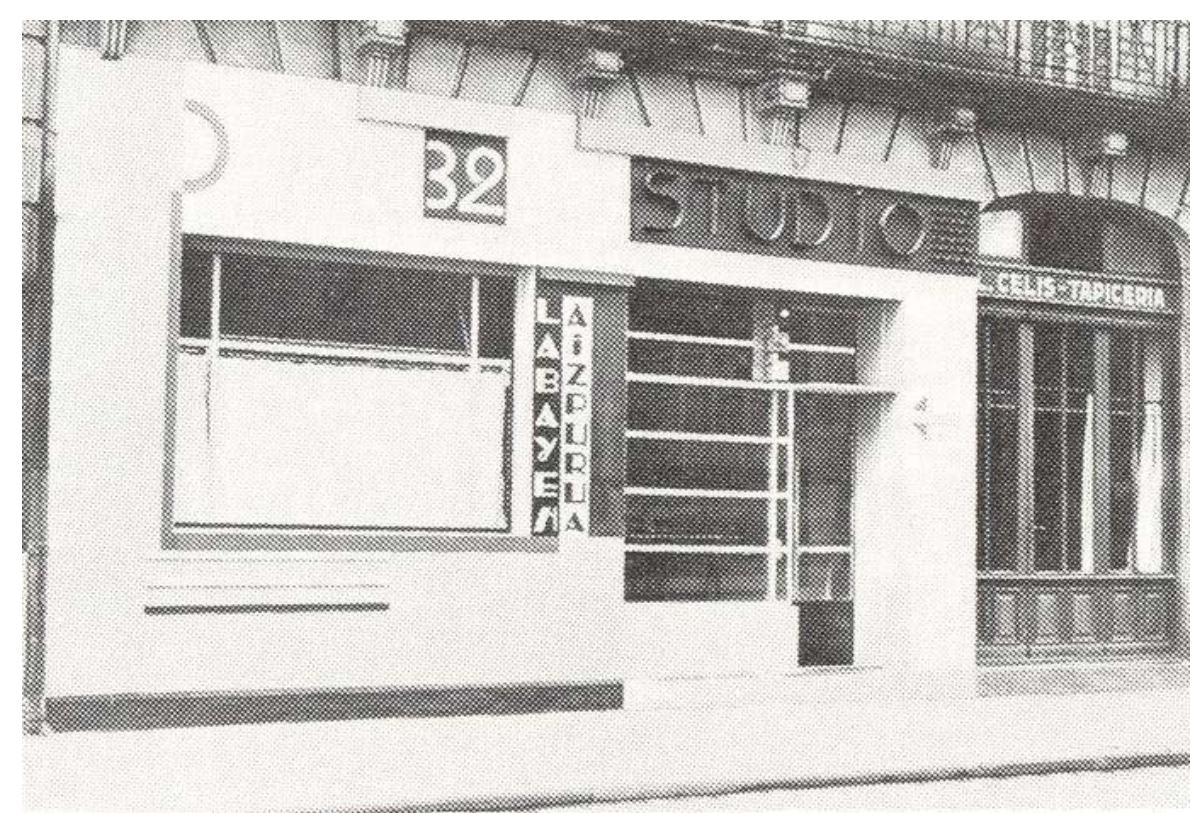

Fig. 6) Studio de Arquitectura. José Manuel Aizpúrua y Joaquín Labayen 1928. Publicado en la revista Het Bouwbeddrijf en 1930

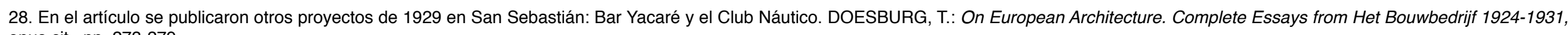
opus cit., pp. 273-279.

29. Así lo constató también Rafael Bergamín al apuntar que los proyectos comerciales tenían que ser el "anuncio viviente en la calle”, y "el cartel que grita al público" lo que se vende dentro. BERGAMíN

J.: "La tienda de automóviles Euskalduna por Rafael Bergamín”, Arquitectura, 99, julio de 1927, pp. 260-264 
habitual en aquellos años. Es posible que los ensamblajes metálicos, al igual que sucedió con otros proyectos de arquitectura moderna, se adquirieran en el extranjero ${ }^{30}$. Aunque también cabe la posibilidad de que la empresa Hijos de J.A. Muguruza, con sedes en Bilbao y Madrid, se encargara de su fabricación. Así lo hizo en el Club Náutico que Aizpúrua y Labayen reformaron más tarde en la misma ciudad, entre finales de noviembre de 1928 y finales de agosto $1929^{31}$.

La fachada metálica del estudio estaba estructurada en dos espacios: la zona de ingreso y la zona de trabajo. La zona de ingreso se dividía en una puerta de acceso de color rojo y en un escaparate en color azul según el dibujo antes citado (Fig.5). La puerta se acompañaba de una flecha, a la vez que un semáforo regulaba al acceso a la tienda ${ }^{32}$.

La zona de ingreso estaba separada de la zona de trabajo por un letrero que recogía en vertical los nombres en mayúsculas de los arquitectos "Labayen" con letras blancas sobre fondo negro, y "Aizpúrua" en letras negras sobre fondo rojo. Le seguía una ventana metálica, con una cortina blanca a media altura que podía ocultar o mostrar el interior de la zona de trabajo. Tres franjas paralelas, coloreadas sobre la fachada, recorrían la parte baja del vano de manera parcial. A ellas se sumaba otra bordeando todo el alfeizar que luego subía por el lateral izquierdo para terminar en un semicírculo abierto. A su altura aparecían el número 32 de la calle en blanco sobre fondo rojo según un boceto, que estaba seguido de unas letras metálicas con la palabra "STUDIO".

La tipografía, que podrían haber realizado firmas locales, resultaba igualmente novedosa. La renovación tipográfica, mucho más presente en las publicaciones y diferentes anuncios de aquellos años, pasó a convertirse incluso en un elemento fundamental de la modernidad de la arquitectura, y así quedó patente en proyectos posteriores de los arquitectos guipuzcoanos que publicaron las revistas $A C$ (1931-1937) o Cortijos y Rascacielos (19301936) $)^{33}$.

El interior del estudio, de escasos $15 \mathrm{~m}^{34}$ y gran altura, seguía la misma compartimentación que la fachada: la zona de ingreso y la zona de trabajo (Fig. 7 y 8). La zona de ingreso destacaba por una decoración pintada de franjas horizontales paralelas hasta la altura de la puerta. Para diferenciar los ámbitos de ingreso y trabajo se utilizó, a modo de tabique, un armario que comentaremos más adelante. De él pendía una tela hasta la pared que hacía la función de puerta. Inicialmente la zona de despacho contaba con dos

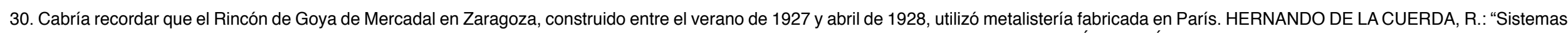

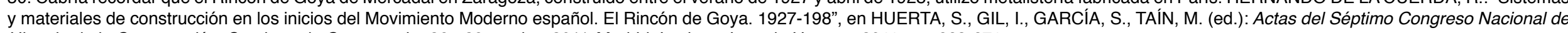
Historia de la Construcción. Santiago de Compostela, 26 - 29 octubre 2011, Madrid, Instituto Juan de Herrera, 2011, pp. 663-671.

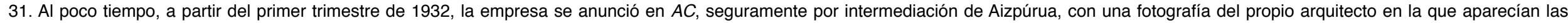

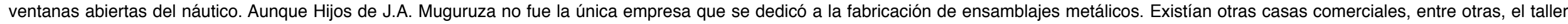

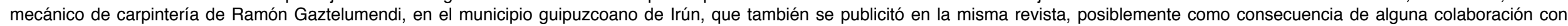
Aizpúrua. AHC. GATCPAC. Resums econòmics de la revista AC.

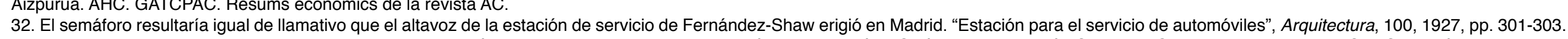

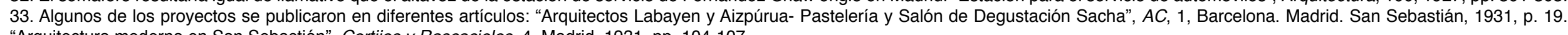
"Arquitectura moderna en San Sebastián", Cortijos y Rascacielos, 4, Madrid, 1931, pp. 104-107.

34. MEDINA MURUA, J.A.: Arkitektura noizko? ¿Cuándo habrá arquitectura? José Manuel Aizpúrua y Joaquín Labayen, opus cit., p. 29. 

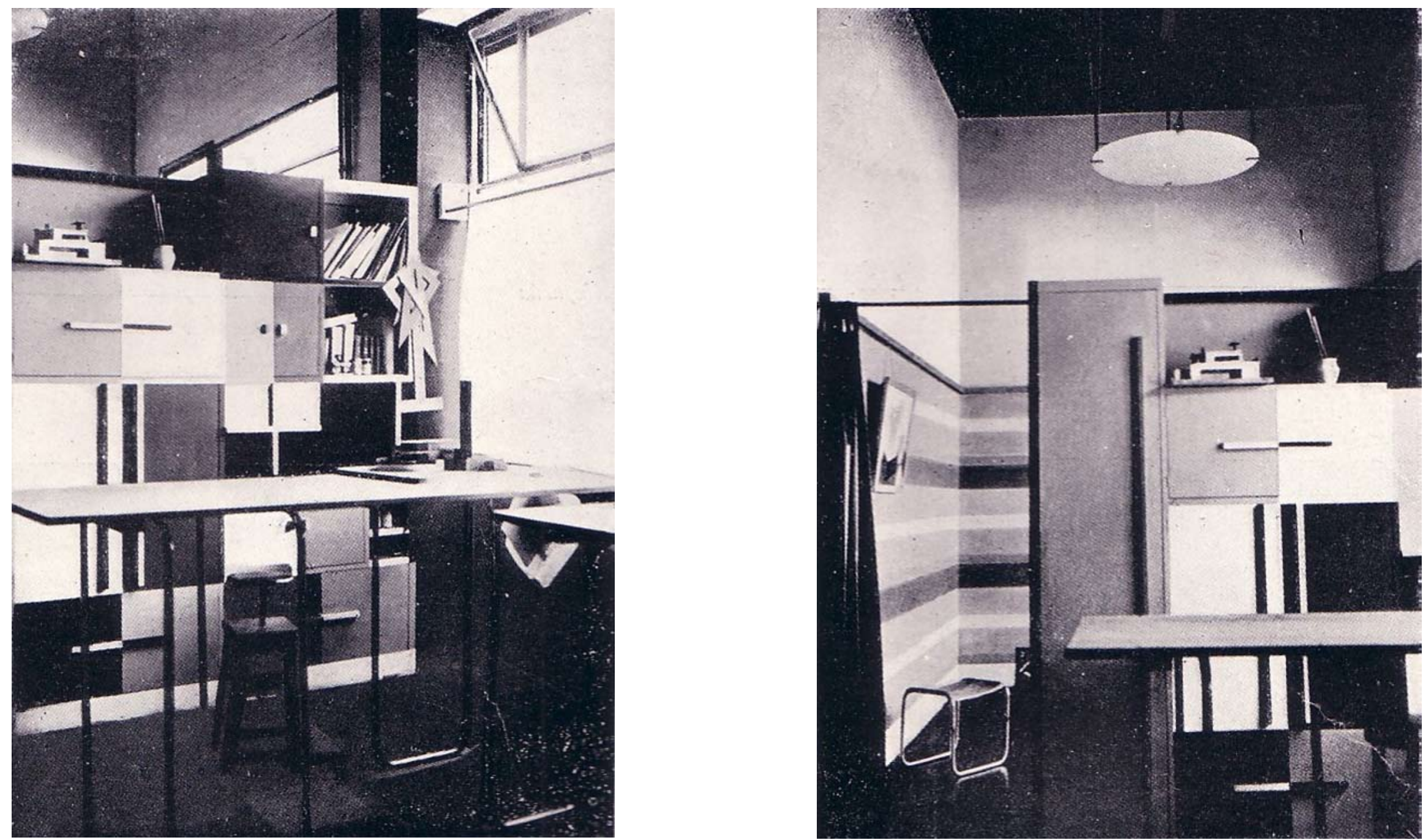

Fig. 7 y 8) Interior del Studio de Arquitectura. José Manuel Aizpúrua y Joaquín Labayen. 1928. Publicado en la revista Arquitectura en noviembre de 1928 
espacios, la zona de trabajo abierta a la ventana de la calle, y una trastienda cerrada a la que también se accedía desde una puerta cerrada con una tela (Fig.9). Posteriormente, enfrente del armario se añadió una escalera de madera de doble tramo, que también contaba con una puerta de madera, quizás para dar acceso a un espacio más de almacenaje o un minúsculo w.c. Desde la escalera se subía a una galería que rodeaba el despacho en forma de "L" ${ }^{\prime 35}$, quizás para acceder a otro espacio de almacenaje sobre la zona de ingreso. Con ello se quiso conseguir optimizar el escaso espacio disponible, en este caso mediante una estructura que nos podría remitir a proyectos de Le Corbusier como La Maison Roche (1923-1925) o el pabellón de L'Esprit Nouveau (1925).

El moderno mobiliario que se utilizó para el estudio también destacó por su adaptación y aprovechamiento del espacio. Como ya hemos adelantado, los ámbitos de ingreso y trabajo se dividieron con un armario doble de la misma altura que la decoración del recibidor. Por lo que los armarios del estudio, además de un elemento funcional y decorativo, también definían, delimitaban y optimizaban el exiguo espacio de trabajo. Este uso del moblaje nos podría recordar al que se utilizó en el pabellón de L'Esprit Nouveau, y en otros proyectos posteriores que Le Corbusier realizó en colaboración con su primo Pierre Jeanneret y la decoradora Charlotte Perriand ${ }^{36}$. Se trataba de "casiers standard" o contenedores modulares y desmontables de media altura que podían ser accesibles por ambos lados, aunque posiblemente no en el caso del estudio. Además en este caso la propuesta de los arquitectos guipuzcoanos destacada por las formas geométricas y seguramente de gran

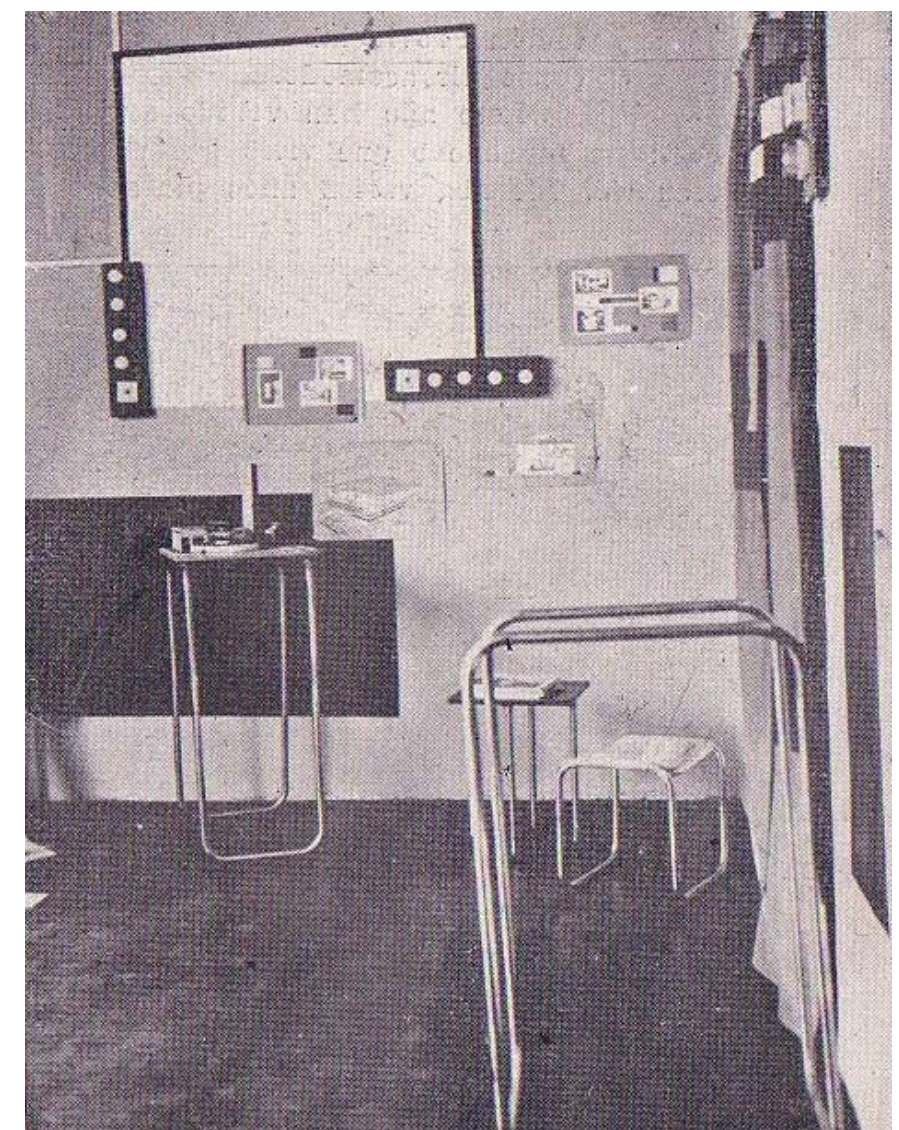

Fig. 9) Interior del Studio de Arquitectura. José Manuel Aizpúrua y Joaquín Labayen. 1928. Publicado en la revista Novedades en septiembre de 1928

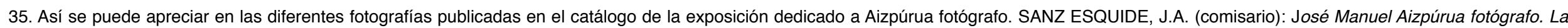
mirada moderna, opus cit.

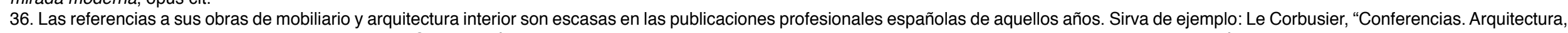

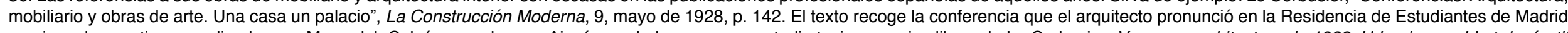

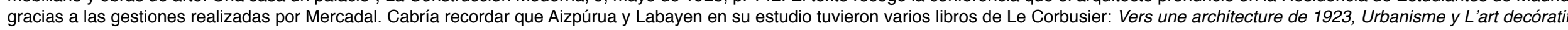
d'aujord'hui de 1925, donde se hace una referencia al mobiliario y a la arquitectura interior. 
colorido, que estaban en consonancia el carácter neoplasticista del proyecto y otras propuestas de Aizpúrua que se recogen en su carné de dibujos de ese mismo $a n ̃ o{ }^{37}$.

En una fotografía que el propio Aizpúrua tomó de la zona de trabajo de su despacho y se publicó en diferentes revistas de la época, se pueden apreciar otros muebles. Entre ellos destaca una mesa auxiliar que sigue el modelo Divantafltje de la colorida Casa Schörder de Rietveld ${ }^{38}$ (Fig.10). Sobre ella aparece el libro de Arthur Korn sobre el vidrio en la nueva arquitectura, que asimila el estudio (Glas im Bau und als Gebrauchsgegenstand, editado en Berlín en 1929), y el número dos de la revista Das Neue Frankfurt (19261936). Alrededor de la mesa podemos distinguir la silla B3 de Marcel Breuer, más conocida como silla Wassily [Kandinsky] que el arquitecto ideó entre 1925-1926 durante su estancia en la Bauhaus, inspirándose en otras propuestas de Rietvled, el mobiliario sanitario o las bicicletas. Otro diseño de Breuer la mesa- taburete B9, aparece en algunas fotografías de la zona de entrada, donde también solían estar algunos modelos de Mies diseñados en acero y mimbre, las sillas modelo MR10 y MR20, que más tarde, Aizpúrua utilizaría en otros proyectos como el Club Náutico ${ }^{39}$. En ellas los clientes podían esperar y ojear los libros y las revistas que había sobre una mesa de tubo de acero y vidrio. Mientras que para trabajar se optó por mesas altas con patas de tubo de acero y cubierta de madera con taburetes también de madera.
En consecuencia, la mayor parte del mobiliario del estudio se caracterizó por la sencillez y ligereza de sus formas, que contribuyeron a crear un ambiente diáfano en un espacio reducido. En palabras de Aizpúrua y Labayen, en referencia al mobiliario del Club Náutico que podríamos extrapolar al estudio, "todo él responde a la idea de algo de fácil manejo; limpieza y conservación" 40 .

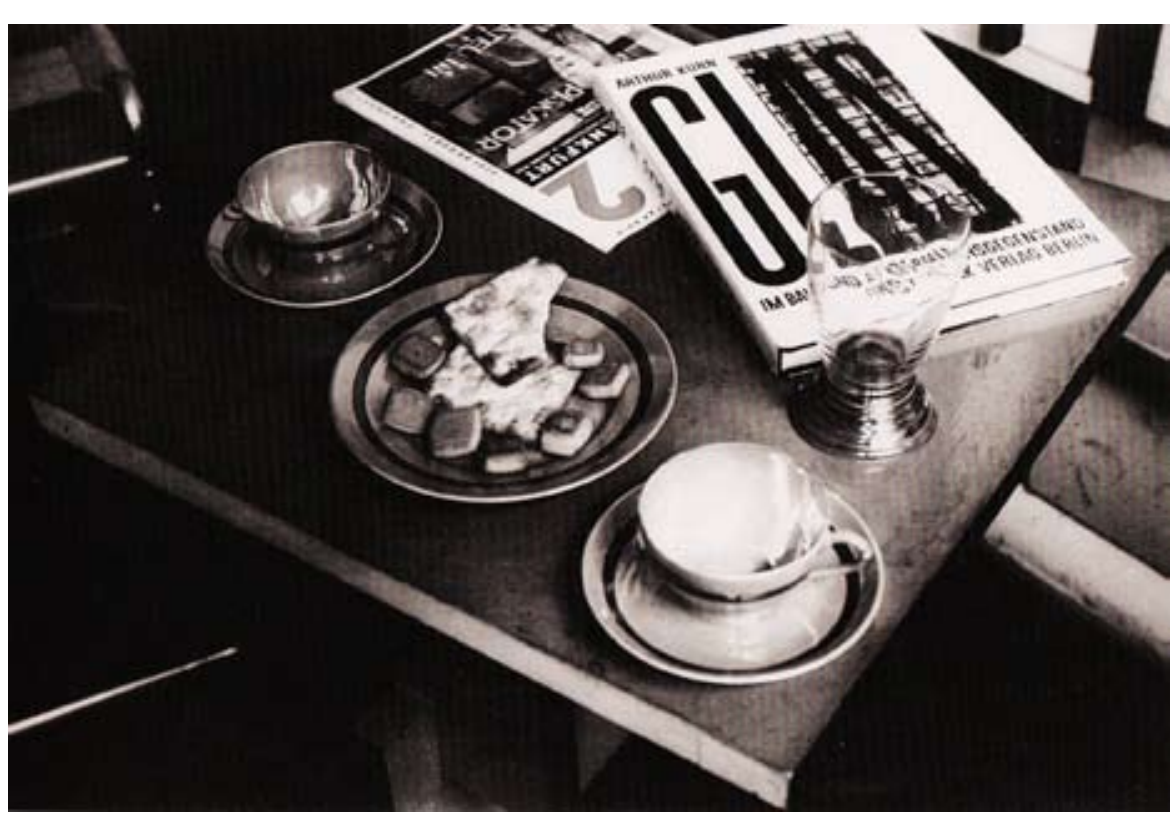

Fig. 10) "Naturaleza muerta pero con espíritu vital". José Manuel Aizpúrua. 1929. Fotografía publicada en la revista La Gaceta Literaria el 15 de abril de 1930

37. Cuaderno de dibujos de José Manuel Aizpúrua Azqueta, opus cit.

38. "Vida, objetos: nueva fotografía", La Gaceta Literaria, 80, 15 de abril de 1930, p. 11. Así como en el primer número de la revista AC

39. En octubre de 1928 José Moreno Villa firmó en la revista Arquitectura la reseña del libro de Werner Gräeff Innenräume publicado en Stuttgart en ese mismo año. La reseña estaba acompañada de

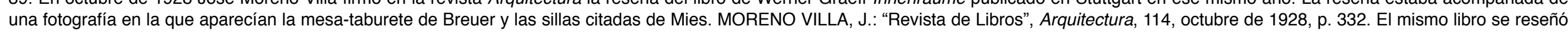
en 1931 en AC: "Bibliografía", AC, 2, segundo trimestre de 1931, p. 36.

40. "Real Club Náutico de San Sebastián. Arquitectos: Aizpúrua y Labayen", AC, 3, segundo trimestre de 1931, pp. 20-25. 
De hecho el suelo del estudio era de linóleo, un material barato, resistente y fácil de limpiar ${ }^{41}$. Asimismo del techo colgaba una moderna lámpara de tulipa opalina totalmente plana y de fácil limpieza, también utilizada en Dancing y Cabaret Tabarín del Frontón Urumea ya citado. La iluminación se completaba con flexos de bases cilíndricas y metal niquelado en las mesas de trabajo. Desconocemos el origen de las lámparas que posiblemente los arquitectos adquirieron, o encargaron a gremios locales.

En la reforma del Náutico, Aizpúrua y Labayen consiguieron el mobiliario de la casa de decoración vienesa Thonet, por lo que es factible que también lo hicieran para el estudio ${ }^{42}$. No en vano, a partir de la década de los treinta Thonet se convirtió en el principal referente de muebles modernos en España, especialmente en mesas y sillas ${ }^{43}$. Asimismo, algunos profesionales utilizaron las propuestas de Thonet y otras firmas como fuente de inspiración o las copiaran. De hecho, es posible que los arquitectos guipuzcoanos además de recurrir a casas de decoración, también solicitaran que algunas empresas locales realizasen, de manera artesanal, determinadas piezas del mobiliario de su despacho. "Hijos de J.A. Muguruza", además de carpinterías metálicas, también fabricaba muebles de acero ${ }^{44}$. Asimismo la empresa "Dámaso Azcue", de la localidad guipuzcoana de Azpeitia, realizó varios muebles para los arquitectos. Más concretamente en 1930 realizó la "silla Sacha" que ocupaba el bar degustación donostiarra del mismo nombre ${ }^{45}$. La colaboración con Azcue siguió en años posteriores, y hacia 1931- 1932, diseñaron una silla de médula de estructura de madera recubierta de mimbre ${ }^{46}$, inspirada en un modelo del arquitecto y diseñador de muebles de la Bauhaus Erich Dieckmann ${ }^{47}$. Por lo que no sería de extrañar que "Dámaso Azcue" hubiera colaborado en proyectos anteriores de Aizpúrua como despacho.

En 1927, un año antes de que se construyera el estudio de Aizpúrua y Labayen, el arquitecto catalán Nicolau María Rubió i Tudurí escribió el libro

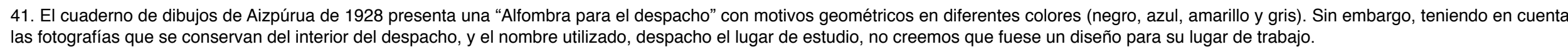

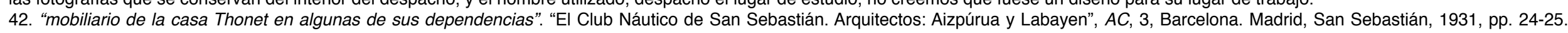
Asimismo la Fundación del Amo de la Ciudad Universitaria de Madrid (1928-29) de Luis Blanco Soler y Rafael Bergamín se completó con modelos de la casa Thonet, a la vez que en el salón de actos se utilizó mobiliario de tubo de acero cromado inspirado en la Bauhaus. ARBAIZA BLANCO-SOLER, S.: Luis Blanco Soler. Tradición y Modernidad. Madrid, Fundación Ramón Aceres, 1999, pp. 101-105.

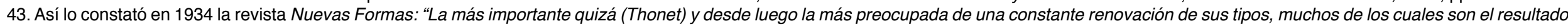
de concursos internacionales por ella organizados". "Muebles de tiendas. Mobiliario estandarizado Thonet”, Nuevas Formas, 9, Madrid, 1934, p. 498. Además la firma se anunció en las páginas de las principales revistas españolas de arquitectura y decoración de la época, y contó con distribuidores en Madrid, Barcelona, Sevilla y Valencia. La casa madrileña Rolaco- Mac, fundada en 1932 fue otro de

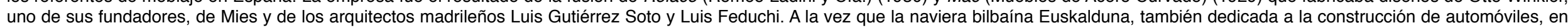
su tienda de Madrid vendió muebles de la firma Standard Möbel (Muebles Standard), de la que era concesionaria, y para la que trabajaba Breuer. En el local del grupo catalán del GATEPAC también se expusieron y vendieron muebles de la casa Thonet, y a partir de 1932, de la firma suiza Wohnbedarf, que se había establecido un año antes en Zúrich y para la que trabajaron Alvar Aalto, Max Bill, Marcel

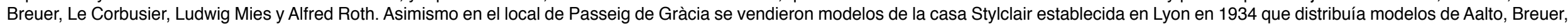
así como de Gropius, Le Corbusier y Perriand. Carta de Barcelona a Aizpúrua fechada el 11.04.1932. AHC. GATCPAC. Correspondencia.

44. En Bilbao también lo hacían "Talleres Elejabarri S.A.", "Talleres Taetz" y la naviera y fábrica de automóviles "Euskalduna".

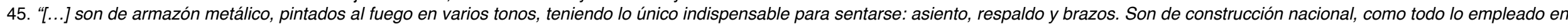
la construcción y decoración de 'Sacha"'. "Arquitectos Labayen y Aizpúrua- Pastelería y Salón de Degustación Sacha", AC, 1, primero- segundo trimestre de 1931, p. 19.

46. Carta de Aizpúrua fechada el 28.07.1931 y carta de Aizpúrua a Torres fechada el 28.06.1932. Carta de Dámaso Azcue a Barcelona fechada el 20.08.1932. AHC. GATCPAC. Correspondencia.

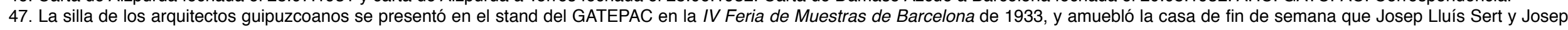
Torres Clavé proyectaron en El Garraf en 1934. "muebles de junco fabricados expresamente para el G.a.t.e.p.a.c. por Dámaso Azcue", "Sección de Noticias. La feria de Muestras de Barcelona", AC, 10 , Barcelona. Madrid. San Sebastián, 1933, pp. 40-41. "Pequeñas casas para 'fin de semana”, en AC., 19, Barcelona. Madrid. San Sebastián, 1935, p. $32-42$. 
Dialegs sobre l'Architectura. En él se refirió a que el desarrollo de la nueva arquitectura que todavía estaba desperezándose, vendría de pequeños proyectos ${ }^{48}$. Asimismo cuando en 1931 el escritor Ramón Gómez de la Serna se refirió en su libro Ismos a las últimas tendencias decorativas y arquitectónicas, se centró en un elemento aparentemente tan secundario como las lámparas de formas cubistas ${ }^{49}$. No en vano, tal como refleja el estudio de Aizpúrua y Labayen, fue más fácil asimilar novedades en elementos secundarios como las lámparas, el mobiliario o la tipografía de pequeñas reformas, que en grandes proyectos arquitectónicos.

Estas propuestas para organizar y decorar pequeños espacios, con el apoyo de publicaciones, exposiciones y conferencias, se convirtieron en los escaparates y en los carteles publicitarios de una nueva estética y de una nueva manera de entender la arquitectura que se desarrollaría en los siguientes años. De hecho la construcción del despacho de los arquitectos guipuzcoanos y su presencia en las revistas Arquitectura y Novedades, junto con la Exposición de Artistas Vascos de 1928, facilitó el encargo de propuestas similares en años posteriores en la capital guipuzcoana. Lo que nos indica la importancia que tuvo la propaganda de las nuevas ideas en el desarrollo del primer racionalismo ${ }^{50}$.
El estudio de los arquitectos guipuzcoanos, fue el primer ejemplo de la nueva arquitectura que se concretó en el País Vasco, y con él se adelantaron muchas de las características que se siguieron en otros proyectos. Pero las novedades introducidas por los arquitectos guipuzcoanos se extendieron, mayoritariamente, a espacios públicos (bares, tiendas, hoteles, clubes o incluso portales de determinadas casas de vecindad), y no así al ámbito doméstico, donde su presencia fue excepcional. De hecho, la mayoría de los proyectos que Aizpúrua y Labayen erigieron en años posteriores fueron reformas de espacios interiores ${ }^{51}$. El resultado fueron establecimientos con una arquitectura interior y un mobiliario que, hasta entonces, tan sólo habían sido conocidas a través de revistas profesionales, mayoritariamente extranjeras.

Se trató, por tanto, de un camino arduo y costoso, ya que los materiales y el moblaje propuesto no eran habituales en aquellos años y necesitaban importarse o fabricarse de manera específica. De hecho es posible que con el estudio los arquitectos empezasen a colaborar con empresas locales para satisfacer sus necesidades que se continuarían en años posteriores, o que lo hicieran al poco tiempo. En todo caso se trató de obras que supondrían un esfuerzo y un sobrecoste. En aquellos años ya se apuntó la carestía del nuevo moblaje, y que los nuevos procedimientos constructivos económicamente eran menos ventajosos y funcionales que otros más tradicionales ${ }^{52}$.

48. RUBiÓ I TUDURÍ, N. M.: Dialegs sobre l'Architectura. Barcelona, Imp. Atlés, 1927, pp. 12-14.

49. GÓMEZ DE LA SERNA, R.: Ismos. Madrid, Biblioteca Nueva, 1931, pp. 138-139.

50. Pocos años más tarde, en septiembre de 1930, Aizpúrua organizó en San Sebastián la Exposición de Arquitectura y Pintura Modernas, en cuyo catálogo e invitación a la exposición, que seguramente redactó el propio arquitecto, podemos leer que su objetivo seguía siendo: "interesar al público". Catálogo. Exposición de Arquitectura y Pintura Modernas. San Sebastián. Ateneo Guipuzcoano.

51. Sala de Juntas AGP (Almacenes Generales del Papel) (1928-1929), Yacaré Bar Club (1929), pastelería y salón de degustación Sacha o la Perla (1930), farmacia Sotos (1933), centro del cultura vasca Euzko Pizkunde (1933), café bar Madrid (1934), sociedad gastronómico- cultural GU (1934), local de Falange en San Sebastián (1934), así como otras reformas que no se llevaron a cabo y que se recogen en la revista Nueva Forma en 1969 y el catálogo de Medina Murua de 2012. La Perla se conserva en el AMSS. D-11, 2426-24. Asimismo se publicaron reseñas sobre los establecimientos en: "Nueva sala y Rascacielos, 4, primavera de 1931, pp. 104-107. E.E., "Exposición de arquitectura moderna", La Construcción Moderna, 18, 30 de septiembre de 1930, p. 278.

52. Así lo apuntaron: GOLS, J.: "El concepte del moble dins les modernes tendències estètiques", Arts i Bells Oficis, diciembre de 1929, p. 245. "Interior y decoración. Despachos", Obras, 31, 1934, pp.

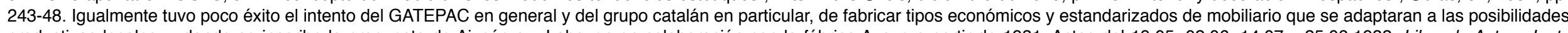
productivas locales, y donde se inscribe la propuesta de Aizpúrua y Labayen en colaboración con la fábrica Azcue a partir de 1931. Actas del 19.05, 02.06, 14.07 y 25.08.1932. Libro de Actas. Junta 
Además la grave crisis económica y constructiva que acompañó al nacimiento de la arquitectura racionalista en el País Vasco y en España, tampoco facilitó su desarrollo, como tampoco lo hizo la inicial valoración negativa de sus propuestas. Desconocemos las referencias que pudo haber en la época hacia el estudio de arquitectura de Aizpúrua y Labayen, pero seguramente no distarían mucho de las que se hicieron sobre la reforma del Club Náutico. El edificio que, siguiendo las ideas de Le Corbusier, imitaba a un barco varado junto al mar, no contó con la simpatía de vecinos y políticos locales que intentaron paralizar el proyecto al considerar que se interrumpían las vistas hacia la bahía con un atentado antiestético, un "mazacote", "un cajón de sorpresas, de asombro, de indignación de gentes que por allí pasan"53.

Con el tiempo la opinión hacia la nueva arquitectura fue cambiando, como también lo fue haciendo la concepción de Aizpúrua y Labayen sobre ella. Ya que con los años, cuando todavía la modernidad no había tomado carta de naturaleza, a partir de 1931, los arquitectos guipuzcoanos se alejaron de las ansias y de la indigestión de la novedad, sin pausa y un tanto miméticas de sus primeros años de juventud, y se acercaron hacia otros modos de entender la arquitectura que estaban experimentado sus colegas en otros países de Europa y que, en ocasiones, contradecían sus experiencias iniciales. Por lo que el estudio de trabajo de Aizpúrua y Labayen fue un laboratorio de ensayos, en el que se ofreció un nuevo uso de formas, materiales, colores y espacios, a la vez que se presentó un nuevo modo de entender la arquitectura y la profesión de arquitecto. Se trató, en definitiva, de la primera aproximación de los arquitectos locales a la modernidad que más tarde, ellos mismos y otros colegas desarrollarían de manera desigual en San Sebastián y en otras ciudades.

Directiva. AHC. Fons GATCPAC. "Tanto los armarios como las mesas están estudiados bajo el punto de vista de la construcción en serie". "Exposición permanente que el Grupo Este del G.A.T.E.P.A.C. ha inaugurado en Barcelona", AC, 2, Barcelona. Madrid. San Sebastián, 1931 p.17. El interés del GATEPAC por la construcción en serie se repite en varios artículos de su revista (números 2, 3 y 8).

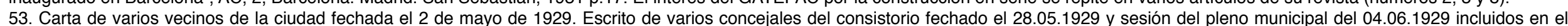

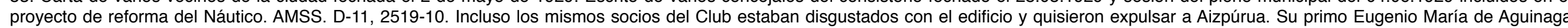

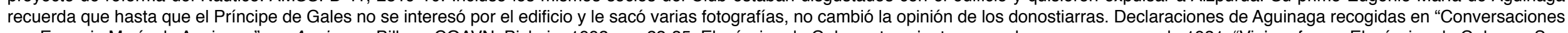
con Eugenio María de Aguinaga", en Aguinaga, Bilbao, COAVN. Bizkaia, 1992, pp. 23-35. El príncipe de Gales estuvo junto con su hermano en enero de 1931, "Viajero fugaz. El príncipe de Gales en San Sebastián", El Pueblo Vasco, San Sebastián, 20 de enero de 1931, p. 1. 